Jorge Casillas

Francisco J. Martínez-López

Rosa Vicari

Fernando De la Prieta (Eds.)

\title{
Management Intelligent Systems
}

Second International Symposium

Springer 


\section{Advances in Intelligent Systems and Computing}

Volume 220

Series Editor

J. Kacprzyk, Warsaw, Poland 
Jorge Casillas · Francisco J. Martínez-López Rosa Vicari · Fernando De la Prieta Editors

\section{Management Intelligent Systems}

Second International Symposium

粤 Springer 


\section{Editors}

Jorge Casillas

Dept. Computer Science and

Artificial Intelligence

University of Granada

Granada

Spain

Francisco J. Martínez-López

Dept. Business Administration

University of Granada

Granada

and

Marketing Group,

Open University of Catalonia

Barcelona

Spain

\author{
Rosa Vicari \\ Department of Computer Systems \\ University of Sao Paulo \\ Sao Paulo \\ Brazil
}

Fernando De la Prieta

Department of Computing Science

University of Salamanca

Salamanca

Spain
ISSN 2194-5357

ISBN 978-3-319-00568-3

DOI 10.1007/978-3-319-00569-0

Springer Cham Heidelberg New York Dordrecht London

Library of Congress Control Number: 2013937324

(c) Springer International Publishing Switzerland 2013

This work is subject to copyright. All rights are reserved by the Publisher, whether the whole or part of the material is concerned, specifically the rights of translation, reprinting, reuse of illustrations, recitation, broadcasting, reproduction on microfilms or in any other physical way, and transmission or information storage and retrieval, electronic adaptation, computer software, or by similar or dissimilar methodology now known or hereafter developed. Exempted from this legal reservation are brief excerpts in connection with reviews or scholarly analysis or material supplied specifically for the purpose of being entered and executed on a computer system, for exclusive use by the purchaser of the work. Duplication of this publication or parts thereof is permitted only under the provisions of the Copyright Law of the Publisher's location, in its current version, and permission for use must always be obtained from Springer. Permissions for use may be obtained through RightsLink at the Copyright Clearance Center. Violations are liable to prosecution under the respective Copyright Law.

The use of general descriptive names, registered names, trademarks, service marks, etc. in this publication does not imply, even in the absence of a specific statement, that such names are exempt from the relevant protective laws and regulations and therefore free for general use.

While the advice and information in this book are believed to be true and accurate at the date of publication, neither the authors nor the editors nor the publisher can accept any legal responsibility for any errors or omissions that may be made. The publisher makes no warranty, express or implied, with respect to the material contained herein.

Printed on acid-free paper

Springer is part of Springer Science+Business Media (www.springer.com) 


\section{Contents}

\section{2nd International Symposium on Management Intelligent Systems (ISMiS‘13)}

Making Accurate Credit Risk Predictions with Cost-Sensitive MLP

Neural Networks . . . . . . . . . . . . . . . . . . . . . . . . . . . .

R. Alejo, V. García, A.I. Marqués, J.S. Sánchez,

J.A. Antonio-Velázquez

Multilevel Clustering on Very Large Scale of Web Data ............. 9

Amine Chemchem, Habiba Drias

Memory, Experience and Adaptation in Logical Agents ............

Stefania Costantini, Giovanni De Gasperis

Mining the Traffic Cloud: Data Analysis and Optimization Strategies for Cloud-Based Cooperative Mobility Management .............

Jelena Fiosina, Maksims Fiosins, Jörg P. Müller

Towards a Knowledge-Driven Application Supporting Entrepreneurs

Decision-Making in an Uncertain Environment

Gianfranco Giulioni, Edgardo Bucciarelli, Marcello Silvestri,

Paola D'Orazio

Training Neural Networks by Resilient Backpropagation Algorithm

for Tourism Forecasting .

Paula Odete Fernandes, João Paulo Teixeira, João Ferreira,

Susana Azevedo

On Semantic, Rule-Based Reasoning in the Management of Functional

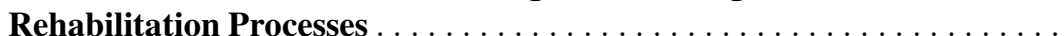
Laia Subirats, Luigi Ceccaroni, Cristina Gómez-Pérez, Ruth Caballero, Raquel Lopez-Blazquez, Felip Miralles 
Advances in Market Segmentation through Nature-Inspired

Intelligence Methods: An Empirical Evaluation

Charalampos Saridakis, Stelios Tsafarakis, George Baltas,

Nikolaos Matsatsinis

Improving Index Selection Accuracy for Star Join Queries Processing:

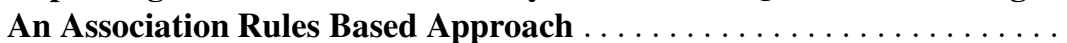

Benameur Ziani, Ahmed Benmlouka, Youcef Ouinten

\section{1st International Workshop on Intelligent Technologies for Enhanced Learning (iTEL'13)}

The Utilization of the Moodle E-Learning System in Isra University . . . .

Mohammad Ali Eljinini, Zahraa Muhsen, Adi Maaita,

Ayman Alnsour, Mohammad Ali Azzam, Khalil Ali Barhoum

Finding People Who Can Contribute to Learning Activities: A First Approach to Enhance the Information about Experts Available in a

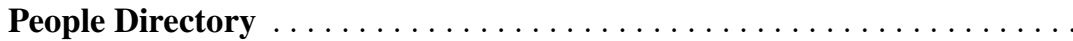

Víctor M. Alonso Rorís, Agustín Cañas Rodríguez,

Juan M. Santos Gago, Luís E. Anido Rifón,

Manuel J. Fernández Iglesias

Providing Event Recommendations in Educational Scenarios . . . . . . . .

Agustín Cañas Rodríguez, Víctor M. Alonso Rorís,

Juan M. Santos Gago, Luís E. Anido Rifón,

Manuel J. Fernández Iglesias

A New Generation of Learning Object Repositories Based on Cloud

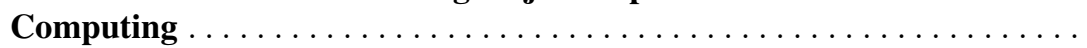

Fernando de la Prieta, Javier Bajo, Paula Andrea Rodríguez Marín,

Néstor Darío Duque Méndez

Technological Platform to Facilitate the Labor Integration of People with Auditory Impairements

Amparo Jiménez, Amparo Casado, Elena García, Juan F. De Paz,

Javier Bajo

Keystrokes and Clicks: Measuring Stress on E-Learning Students

Manuel Rodrigues, Sérgio Gonçalves, Davide Carneiro,

Paulo Novais, Florentino Fdez-Riverola

Integral Multi-agent Model Recommendation of Learning Objects, for Students and Teachers

Paula Rodríguez, Néstor Duque, Sara Rodríguez 
TANGO:H: Creating Active Educational Games for Hospitalized

Children

Carina Soledad González, Pedro Toledo, Miguel Padrón, Elena Santos,

Mariana Cairos

Author Index 


\title{
A New Generation of Learning Object Repositories Based on Cloud Computing
}

Fernando de la Prieta, Javier Bajo, Paula Andrea Rodríguez Marín, and Néstor Darío Duque Méndez

\begin{abstract}
This work presents a proposal for an architecture based on a cloud computing paradigm that will permit the evolution of current learning resource repositories. This study presents current problems (heterogeneity, interoperability and low performance) of existing repositories, as well as how the proposed model will try to solve them.
\end{abstract}

Keywords: Learning Object Repository, Cloud Computing, eLearning.

\section{Introduction}

It has become common in recent years to encapsulate educational resources in the form of learning objects (LO), a process that facilitates their management and reuse. That is, the systematic management of learning resources makes their dissemination possible.

To facilitate these dissemination tasks, the LO are stored in educational repositories. However, these repositories present problems at a technical level, such as low-level performance, unavailability, security, reliability, etc. At the same time,

\section{Fernando de la Prieta}

Department of Computer Science and Automation Control, University of Salamanca.

Plaza de la Merced s/n, 37007, Salamanca, Spain

e-mail: fer@usal.es

Javier Bajo

Department of Artificial Intelligence. Techinical University of Madrid.

Campus Montegancedo, Boadilla del Monte, Madrid, Spain

e-mail: jbajo@fi.upm.es

Paula Andrea Rodríguez Marín · Néstor Darío Duque Méndez

National University of Colombia, Colombia

e-mail: \{parodriguezma, ndduqueme\} @unal . edu.co 
the paradigm as a whole also shows many deficiencies like the existence of too many schemas of metadata or interoperability specifications, or even internal architecture of the repositories.

This environment, which is complex not only at the technical level but at the conceptual level as well, has led to a low level of implantation of this technology despite the great advantages derived from its use. Thus, the objective of this study is to propose and subsequently develop a new model which can make it possible to reduce or remove the existing problems. To this end, Cloud Computing paradigm is the key to offering effective and efficient services such as storage, and the search and retrieval of educational resources

The next section presents the state of the art within this context, as well as a study to demonstrate the problems observed in repositories. Section 3 presents the detail of the architecture and, finally, section 4 the conclusions and future work.

\section{Learning Objects and Repositories}

The encapsulation of education resources in the form of LO makes their reutilization possible. Many authors have recently been presenting their vision regarding this concept [8][4][7], which has led to the appearance of a number of definitions. The aim of this study is not, however, to establish what an LO is, rather to simply remark that there is a clear consensus that an LO must be the minimal reusable unit with a specific learning objective.

There is also a consensus that each LO has to be associated with an external structure of metadata. This metadata allows making a first approach to the educational resource. In other words, the metadata permits improving the utility of the resource, since it makes its retrieval, search, exchange, and hence, its reutilization, possible. The metadata schema is standardized. In fact, there are currently many standards such as DublinCore[3], IEEE LOM[8], etc. The existence of standards facilitates the management of the resources, enabling the interoperability among systems that use compatible standards.

Although at first sight these standards can be seen as an advantage, reality shows that in some cases they are the problem, as many existing standards are not compatible among themselves. The ADLNet ${ }^{1}$ initiative was developed in order to solve these problems and to coordinate the effort of metadata standards and, in general, the use of IT in the educational context. It is important to note that not only is the existence of metadata standards necessary in order to reuse contents, but the data that the authors assign to each descriptor is very important as well. To this end, it is necessary to follow a traceable process from the creation of an educational resource to the creation of its metadata in order to establish a metadata structure that is consistent, relevant and interpretable. [2].

As with traditional education resources, LOs are stored in libraries, in this case digital libraries called repositories. A digital repository can be defined as a place

\footnotetext{
${ }^{1}$ Advanced Distributed Learning Network. http: / / www . adlnet . org /
} 
where a digital resource can be stored, searched and retrieved. These systems must also support the import, export, identification and retrieval of content. [11]. The LOs are usually stored in a Learning Object Repository (LOR). JORUM project [10] states that an LOR is a set of LOs with detailed and external information (metadata) that is accessible from the Internet. In addition to housing the metadata, an LOR can also store the educational resource. In general terms, an LOR must implement the following task [iError! No se encuentra el origen de la referencia.]: Search/Find, Ask, Retrieve, Send, Store, Collect and Publish.

The deployment infrastructure can basically be either distributed or centralized. Taking into account that an LO is formed by a digital resource and its metadata, there are four kinds of possible infrastructures [6]: (i) centralized resources and centralized metadata, (ii) centralized resources and distributed metadata, (iii) distributed resources and centralized metadata and (iv) distributed resources and distributed metadata. Furthermore, three kinds of storage strategies can be distinguished [6]: (i) File-based, which uses files with predefined formats and an indexbased management; (ii) Database-based, which uses any kind of database, and is the most extended method; and (iii) Persistent objects-based, where the LO are stored as serialized objects.

A controversial aspect is the interoperability among LORs. Firstly, it is necessary for a repository to use at least one standard in the stored metadata. And secondly, there must be an interface from where an external search agent (a client or another LOR) can access the stored information. This interface is currently implemented through high-level interoperability layers that allow access from outside the LOR. There are different standards or specifications that focuses on this interoperability layer:

- OAI-MPH (The Open Archives Initiative Protocol for Metadata harvesting)[12]. This protocol provides a technology-independent framework for retrieving documents or resources, thus enabling interoperability among systems. The protocol is open and the repository is not limited to educational resources.

- IMS DRI (IMS Digital Repository Interoperability) [9]. This is based on existing communication technologies and on previous specifications of the IMS consortium. This protocol is immature and is still in its initial stages of development.

- SQI (Simple Query Interface) [4]. The kernel of SQI is formed by a set of abstract methods based on web services. These methods are not associated with any underlying technology. It is also is neutral in terms of the format of results as well as query language. This interfaces supports synchronous/asynchronous and stateful/stateless queries. The authentication is based on a session with the aim of isolating the harvesting of contents from the management tasks.

The use of an abstraction layer between LOR and the client system avoids the need to take the internal infrastructure of the repository into account, and allows clients to perform queries to many repositories in parallel. In other words, the clients can perform federated searches [1][5]. 


\subsection{The Reality of LOR Interoperability}

The state of the art shows a high heterogeneity in existing standards. Therefore, a study of LOR has been performed in order to analyze the real situation. The study includes the analysis of the following LORs: Acknowledge, Agrega, Ariadne, AriadneNext, CGIAR, EducaNext, LACLO-FLOR, LORNET, MACE, Merlot, Nime, OER Commons and Edna Online. It consists of performing 60 queries to each LOR through an SQI layer that the repositories provide. The query patterns are Unesco codes.

Firstly, the general characteristics of each LOR are analyzed; all of them use IEEE LOM as metadata schema and VSQL [15] as query language. Additionally, the majority of them are stateless $(65 \%)$, and all of them have synchronous interfaces, but only 4 have the asynchronous interface.

Considering that the SQI specification does not force the implementation of all methods of the specification, the SQI methods that these repositories have implemented are checked. The results radically change the outlook because 6 of the 14 repositories do not work or are unavailable and they have to be removed from the scope of this study (Ariadne, AriadneNext, EducaNext, Nime and EdNa Online). MACE and LOCLO-FLOR produce an error in the authentication, although the process is done correctly. After this step, this test is reduced to only four repositories Acknowledge, Agrega, LORNET and Merlot. The latter three are perfectly valid and all SQI methods work perfectly; however the repository Acknowledge only implements the essential methods to perform queries.

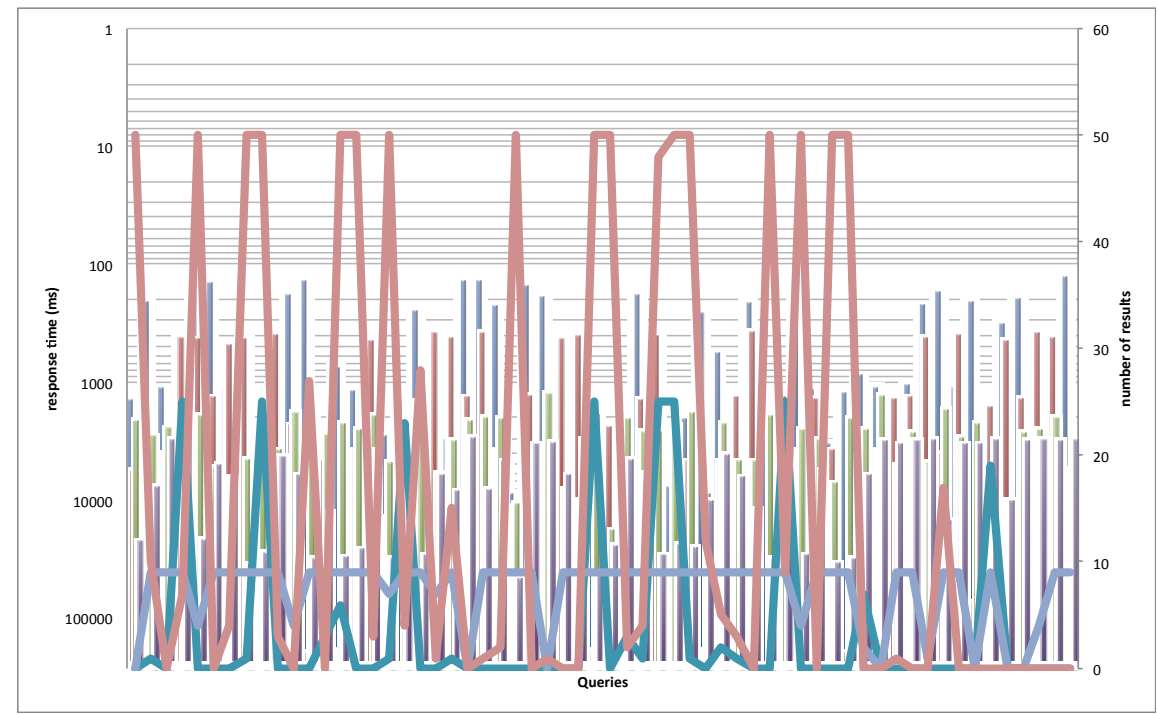

Fig. 1 Repositories performance 
Finally, to summarize this study, Figure 1 shows the performance of each LOR. The lines are the number of results and the bars are the response times. The stateful repositories are slower than stateless repositories, with an average 19,1685 seconds compared to 3.053 seconds respectively, because they have to authenticate the client before performing the query. The average of the results is $9.56 \mathrm{LOs}$ retrieved per query.

\section{An Opportunity Focused on Cloud Computing}

As it is possible to observe, the performance of the LOR is not appropriate. In order to deal with this problem, new LOR architectures have to be proposed and developed. This new generation of LOR must ensure the availability of resources and interoperability, permitting federated searches from external clients.

Lately, within the services in the context of Internet, Cloud Computing is emerging as key paradigm of the present century. According to NIST $^{2}$ [13], Cloud computing is a model for enabling ubiquitous, convenient, on-demand network access to a shared pool of configurable computing resources (e.g., networks, servers, storage, applications, and services) that can be rapidly provisioned and released with minimal management effort or service provider interaction. This cloud model is composed of five essential characteristics, three service models, and four deployment models. This definition includes three levels of computational services (Software, Platform and Infrastructure).

However, beyond the kinds of services, the key characteristic of this new paradigm is the quality of services. Cloud services are able to offer the same level of quality independently of instant demand. In practice, end users make use of Cloud services that are always available and unlimited.

Taking into account the weakness that has been demonstrated in this study with regard to the performance, availability and interoperability of existing LORs, this study proposes a new architecture based on Cloud Computing.

This new architecture will make use of the services that +Cloud platform [14] provides, such as storage and databases. This platform is based on the Cloud Computing paradigm. This platform allows offering services at the PaaS and SaaS levels. The IaaS layer is composed of a physical environment that allows the abstraction of resources into virtual machines.

The SaaS layer is composed of the management applications for the environment (virtual desktop, control of users, installed applications, etc.), and other more general third party applications that use the services from the PaaS layer. The components of this layer are:

- the IdentityManager, which is the module of +Cloud in charge of offering authentication services to clients and applications.

- the File Storage Service (FSS), which provides an interface for a container of files, emulating a directory structure in which the files are stored with a set of metadata, thus facilitating retrieval, indexing, search, etc.

${ }^{2}$ NIST, National Institute of Standards and Technology (http: / / www .nist.gov/) 
- the Object Storage Service (OSS), which provides a simple and flexible schemaless data base service oriented towards documents.

\subsection{Proposal: CLOR}

This study proposes the development of a new platform called CLOR (Cloudbased Learning Object Repository) based on +Cloud as its underlying architecture. Figure 2 shows a diagram with the main components of this modern architecture. The details of each component are presented as follows:

- CLOR Management is the kernel of the architecture. It is framed at the platform level within Cloud services. Its main task is to encapsulate the communication with the lower layers of the Cloud platform; at the same time, it is in charge of providing a set of functionalities in terms of web services to the upper layers, that is, to the end user interfaces.

o FSS will be used to store the educational resources. FSS also encapsulates the traditional complexity of the file system storage; this component only has to call web services in order to retrieve or store resources. Furthermore, because of other FSS functionalities, such as file versions, metadata associated with each resource, etc., it will be possible to increase the power of the service. Finally, it should be noted that the elasticity of the FSS implies no limitation regarding storage capacity.

o OSS will be used to store the metadata associated with each learning resource. OSS makes use of a nonSQL database that permits storing the metadata en JSON format. The main advantage is that it permits storing any kind of metadata independent of its structure or schema, that is, its standard. Furthermore, queries about the LO will be performed very quickly thanks to the underlying database.

This component will be complemented with different interoperability layers, such as SQI or OAI-MPH, which will ensure the communication with other LORs and federated searches from external clients.

- CLOR GUI is the graphical user interface of the end users. The key architectural characteristic is that it will be independent of the bottom layer (in other words, the CLOR Management) and communication will be carried out through web services. The management of the users will be delegated to the Cloud, specifically, to the identity manager.

CLOR will present two independent interfaces:

- Storage CLOR in charge of managing the repository (storage and creation of metadata).

- Search CLOR will provide an interface to perform queries not only in this proposed repository, but also in the resources of other resources by means of the interoperability layers. This interface component will, in the future, also provide other functionalities such as a recommendation system, a key functionality that has recently emerged [1]. 


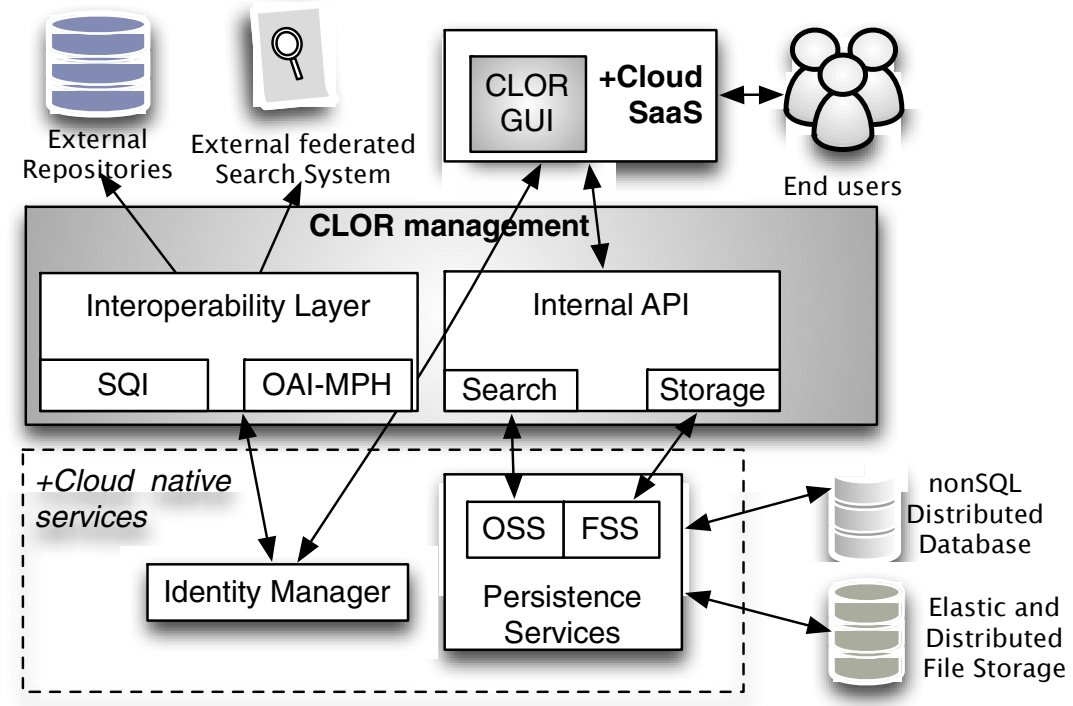

Fig. 2 CLOR architecture

\section{Discussion, Advantages and Future Work}

This study has presented an innovative architecture that constitutes an evolution over current storage system for educational resources. This new model, will enable the observed problems, which have been demonstrated in this study, to be solved:

- High heterogeneity in terms of number and characteristics of existing standards. The proposed model allows dealing with the heterogeneity of current and future standards since it is based on a non-relational database.

- Low performance. Cloud computing paradigm allows offering services with the same level of quality independently of its demand. The development of the LOR based on this paradigm will make it possible not only to offer an effective service effective, but to offer an unlimited storage capacity as well.

- Interoperability among repositories. The low linkage among components permits implementing many interoperability layers without needing to upgrade to other modules.

- Complementary services. This model will make it possible to include other functionalities in its own repository that until now were not possible, such as recommendation model, space of storage for each user in the cloud, a collaborative model for creating learning resources and metadata, etc.

Future work will be focused on finishing the development of the proposed repository and evaluating it not only at a technical level, but also at a functional level by using end users that are teachers and students. 


\section{References}

1. Gil, A.B., Rodríguez, S., de la Prieta, F., De Paz, J.F.: Personalization on E-Content Retrieval Based on Semantic Web Services. International Journal of Computer Information Systems and Industrial Management Applications 5(2013), 243-251 (2010) ISSN 2150-7988

2. Berlanga, A.J., López, C., Morales, E., Peñalvo, F.J.: Consideraciones para reforzar el valor de los metadatos en los objetos de aprendizaje (OA). Salamanca. Universidad de Salamanca. Depto. deInformática y Automática (2005)

3. Dublin Core Metadata Initiative. DCMI Metadata Terms

4. European Committee for standardization - Cen Workshop Agregament. A simple Query Interface Specification for Learning Repositories. Ref. No.: CWA 15454:2005 E (2005)

5. De la Prieta, F., Gil, A.B., Rodríguez, S., Martín, B.: BRENHET2, A MAS to Facilitate the Reutilization of LOs through Federated Search. Trends in Practical Applications of Agents and Multiagent Systems, 177-184

6. Frango, I., Omar, N., Notargiacomo, P.: Architecture of Learning Objects Repositories. Learning Objects: standards, metadata, repositories \& LMS, pp. 131-155 (2007)

7. Frango, I., Omar, N.: Architecture of Learning Objects Repositories. Learning Objects: standards, metadata, repositories \& LMS, 131-155 (2007)

8. IEEE Learning Objet Metadata (LOM). Institute of Electrical and Electronics Engineers (2002), http: / / Itsc. ieee.org

9. IMS Digital Repositories Interoperability. Riley, K., McKell, M., y Mason, J. Core Functions Information Model. Version 1.0 Final Specification (2003)

10. JISC Online Repository for [learning and teaching] Materials (2004)

11. Joint Information System Committee. What is a Digital Repository? Digital Repositories. Helping Universities And Colleges (2010)

12. Lagoze, C., Van de Sompel, H., Nelson, M., Warner, S.: The Open Archives Initiative Protocol for Metadata Harvesting (2002)

13. Mell, P., Grance, T.: The NIST definition of Cloud Computing. In: NIST Special Publication 800-145 (September 2011)

14. Heras, S., De la Prieta, F., Julian, V., Rodríguez, S., Botti, V., Bajo, J., Corchado, J.M.: Agreetment technologies and their use in cloud computing environments. Progress in Artificial Intelligence 1(4) (2012)

15. Simon, B., Massart, D., Van Assche, F., Ternier, S., Duval, E.: Authentication and Session Management. Version 1.0. (2005) 


\title{
Technological Platform to Facilitate the Labor Integration of People with Auditory Impairements
}

Amparo Jiménez, Amparo Casado, Elena García, Juan F. De Paz, and Javier Bajo

\begin{abstract}
This paper presents a technological platform aimed at obtaining an online workspace for exchanging digital contents in an easy, intuitive and accessible manner. The main objective of the platform is to provide facilities to inform, train and evaluate the competencies of disabled people, and more specifically those skills required to facilitate the labor integration of individuals with auditory disabilities. The platform also focuses on providing training processes that facilitate the incorporation of disabled people to labor environments. The platform presented in this paper has been tested in a real environment and the results obtained are promising.
\end{abstract}

Keywords: disabled people, auditory disability, competence, intelligent systems, learning and training processes.

\section{Introduction}

Education and training for disabled people has acquired a growing relevance during the last decade, especially for labor integration. Information and communication

\footnotetext{
Amparo Jiménez · Amparo Casado

Universidad Pontificia de Salamanca, Salamanca, Spain

e-mail: $\{$ ajimenezvi, acasadome\} @upsa.es

Elena García · Juan F. De Paz

Departamento de Informática y Automática, Universidad de Salamanca

e-mail: \{elegar, fcofds\} @upma.es

Javier Bajo

Departamento de Inteligencia Artificial, Universidad Politécnica de Madrid

e-mail: javier.bajo@upm.es
} 
technologies play a very important role in this evolution. Disabled people represent a considerable percentage of the current population and require special education.

During the past year, we have developed a research project linked to two different realities: professional training and proper professional performance with the special needs of some people with difficulties to access to employment. We selected as a target group the auditory impaired people and we focused in an specific job profile and job performance: Auxiliary Operations and General Administrative Services.

Subsequently we developed a technology-based training tool that allows the disabled people to effectively develop their professional performance, as well as to improve the professional training previous to the integration into the labor environment.

Thus, we propose a technological platform that focuses on obtaining on-line workspace for exchanging digital contents in an easy, intuitive and accessible manner. The main objective of the platform is to provide facilities to inform, train and evaluate the competencies of disabled people, and more specifically those skills required to facilitate the labor integration of individuals with auditory disabilities. This process may take place in the workplace or in the place of address via television, computer and mobile phone.

The rest of the paper is structured as follows: Section 2 presents the background of the problem taken into consideration. Section 3 presents the problem formalization. Section 4 describes the proposed technological platform. Finally, Section 5 presents the preliminary results and the conclusions obtained.

\section{Background}

First of all we must define the group taken into consideration in this study. As indicated by Calvo Prieto [1], the term auditory disabled refers to anyone who sees the word without sharpness enough or as indicated by the World Federation of the Deaf (Word Federation of the Deaf, EUD) person with hearing difficulty that can be alleviated with technical aids (FESORCV) [2].

We understand as those for people with a degree of disability (now disabled) greater than $33 \%$ by deafness or hearing limitations that encounter communication barriers (Spanish Law 27/2007, of 23 October, recognizing the Spanish sign languages and regulates the means of support for oral communication of the deaf, hearing impaired and deafblind, 2007) [3], or as a term currently used for the Confederation of Deaf People (CNSE) [4] or the Spanish Confederation of Deaf Families. (FIAPAS, 2004) [5].

To establish a proper design of professional guidance, we need to perform a detailed analysis of the specific characteristics of the position, profile and skills associated with their good work performance. Professional qualification is the "set of skills with significance in employment that can be acquired through training or other types of modular training, and through work experience" (Spanish Law 5/2002 on Qualifications and Vocational Training ) [6]. 
From a formal point of view, the qualification is the set of professional competencies (knowledge, skills, abilities, motivations) that allow us to perform occupations and jobs with a valuable labor market impact and that can be acquired through training or work experience.

It implies, as noted by Levy-Leboyer [7] "a set of observable behaviors that are causally related to a good or excellent performance in a specific job and a specific organization" covering the full range of their knowledge and skills in personal, professional or academic, acquired in different ways and at all levels, from basic to top.

\section{Problem Formalization}

To formalize the problem we have relied on the National Catalogue of Professional Qualifications and professional qualifications, and we have selected the professional qualification Auxiliary Operations and Administrative Services for the Family General Administration and Management Professional with Level 1.

Our aim is not to find a professional qualification (which corresponds to the Initial Professional Qualification Programmes-PCPI-) but, based on the characteristics and requirements related to this position as identified in the Royal Decree 229/2008 of 1 February (BOE, No. 44 of February 20, 2008) [8], to identify some actions, strategies and more appropriate training resources, technologically updated and valid for the training and evaluation of the disabled individuals.

From our point of view, it is essential to follow the determination of the legal requirements and current proposals in the employment context. This allow us to train competent workers taking into account the parameters required in our sociolabor context, as well as the parameters shared by any worker (with or without disabilities) to develop such activities. We define, therefore, and employment and social integration strategy for people with different skills but that can afford with guarantees the demands of the position. Therefore, we respect the design of general competencies, skills units and professional achievements with performance criteria proposed in the Spanish National Catalogue of Professional Qualifications, as well as the different existing guidelines in Spain and those proposed by various international organizations.

Taking as starting point the document from the Spanish National Institute of Vocational Qualifications, we define an structure of the professional qualifications that will serve to design programs, resources, methodologies and educational interventions. In this sense, we have made a major effort to assign to each qualification a general competence. This competence includes the roles and functions of the position and defines the specific skills or competency units.

Described also the professional environment in which you can develop the skills, relevant productive sectors and occupations or jobs relevant to access it.

We have also described the professional labor environment in which the qualification will be evaluated, relevant productive sectors and occupations or jobs relevant to accessible obtaining the qualification. 
Furthermore, in a complementary manner, we analyzed the professional achievements for each unit of competence along with their performance criteria.

We started with the following situation:

\section{AUXILIARY OPERATIONS FOR ADMINISTRATIVE AND GENERAL SERVICES professional qualification.}

\section{General competence:}

To distribute, reproduce and transmit the required information and documentation in the administrative and management task, internal and external, as well as to perform basic verification procedures on data and documents when senior technicians require it. These tasks are carried out in accordance with the existing instructions or procedures.

\section{Competence units:}

- To provide support for basic administrative operations.

- To transmit and receive operational information to external agents to the organization.

- To perform auxiliary operations for reproduction and archiving data on conventional computational support.

\section{Professional field:}

This individual operates as an employee in any company or private/public entity, mainly in offices or departments oriented to administrative or general services.

\section{Productive Sectors:}

It appears in all the productive sectors, as well as public administration. It is necessary to remark the high degree of inter-sectoriality.

\section{Relevant occupations and possitions.}

- Office Assistant.

- General services assistant.

- File assistant.

- Mail classifier and / or message.

- Ordinance.

- Information Assistant.

- Telephonist.

- Ticket clerk.

Fig. 1 Auxiliary Operations for Administrative and General Services professional qualification

However, we considered that, looking for a more specific training support, it is necessary to complete this information with the detailed description of the most common tasks that arise in professional performance. Thus, describing the specific tasks, we have established the type of support that this group of disabled people requires to carry out an effective performance of the assigned tasks. Finally, we have established the most appropriate training strategies. Thus, we have described the 
most common tasks related to the professional profile and professional qualification presented in the previous table. The following example illustrates our proposal:

\section{Competence Unit: To provide support for basic administrative operations}

Professional Development 1: To periodically register the Information updates of the organization, department, areas, personnel, according to the instructions previously received, with the aim of obtaining key Information to improve the existing services. Realizar un organigrama de la empresa o departamento

1. Make a list of phone and fax references of the various members of the company

2. Update the directory of people

3. To register the physical location of people and areas within the company.

4. To update the physical location of people and areas within the company.

5. Safe-keeping of keys.

6. Opening and closing the workplace and departments.

7. Bring documentation to other centers in the city (unions, Delegation, City Council, County Council, etc.)

8. Turn off and turn on the lights

9. Opening and closing windows

10. Open and lock any room.

11. To register the inputs and outputs of the employees.

12. To register a list for people who want to take the annual medical review.

\section{Technological Platform}

Based on the problem formalized in section 3 we obtained a technological platform. It is a software platform specifically designed to create intelligent environments [11] oriented to facilitate the labor integration of people with auditory disabilities. The main objective of the Ambient Intelligence is to achieve transparent and ubiquitous interaction of the user with the underlying technology [11]. In this paper we use Ambient Intelligence to design a software technology specialized on determining the professional qualification, and providing on-line tools focused on transmitting signed orders that are easily accessed via mobile devices. Basically, the proposed platform consists of a training tool via web, and a communication tool to send signed orders via mobile phone. In the following points we describe the main elements of the application.

\section{- Order signing}

Once the competences to evaluate were identified, and the related professional developments were defined, we proceeded to signing the actions and tasks that can be performed by the disabled person.

To make the signing we counted on the cooperation of the Federation of the Deaf of Castile and Leon (FAPSCyL) [12], who have participated in the signing process. The process followed consisted on recording a series of videos in which the sign interpreters transmit specific orders for each of the actions to be carried 
out by the disabled person. The recording was done in blocks, taking into account the professional developments taken into consideration.

Once the recording process finished, we proceeded to edit the videos obtained by separating each action individually and including subtitles in Spanish.

\section{- Web platform}

In this task we obtained the design and development of a web platform that allows us to transmit work orders to the auditory disabled person using sign language format. The orders are transmitted via the Internet, television or mobile devices. This is a simple Web page, based on Drupal CMS [13], which consists of the following sections:

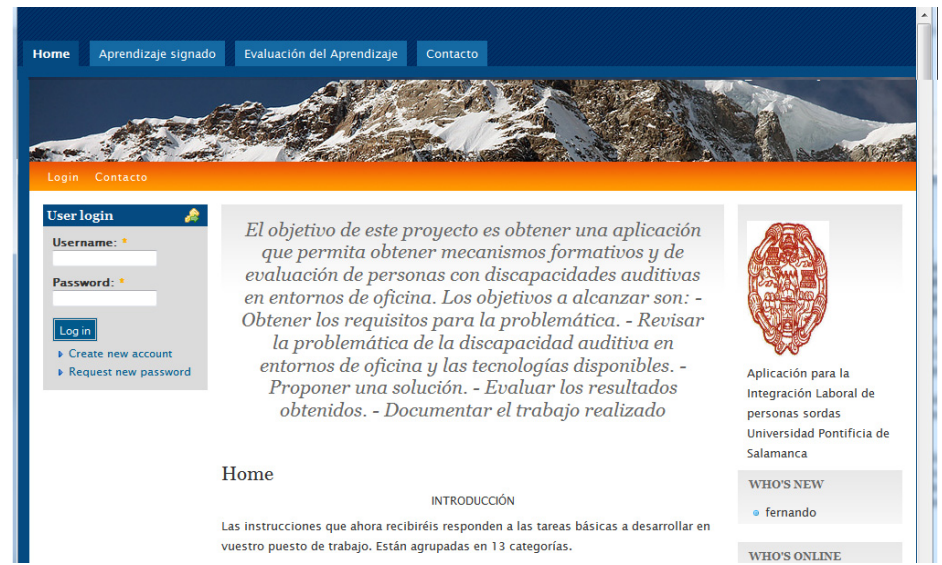

Fig. 2 Main page of the platform for auditory disabled people

Figure 2 shows a web platform with differnt elements: a heather, menus for Home, Signed learnig, Learning evaluation and Contact:

- Home. It is the door to the web platform. It provides a user management section. A user authentication is required. Besides, this section describes the main objective of the platform and provides general instructions about its usability.

- Signed learning, provides instructions and exercises that are presented to the auditory disabled user bya means of videos. The videos show a signing interpreter transmiting orders.

- Learning evaluation. In this section a series of series are presented to the user. The surveys allow us to evaluate the user satisfaction degree and the effectiveness of the learning process.

- Contact. It provides the contact details for the platform.

The appearance of the platform is simple, trying to facilitate the accessibility and usability. The navigation through menus and contents is easy and intuitive. All the pages have been designed with the same structure, trying to facilitate a 
familiar environment and similar interaction patterns independently of the page or section in the platform. The next paragraphs describe the contents included in the platform:
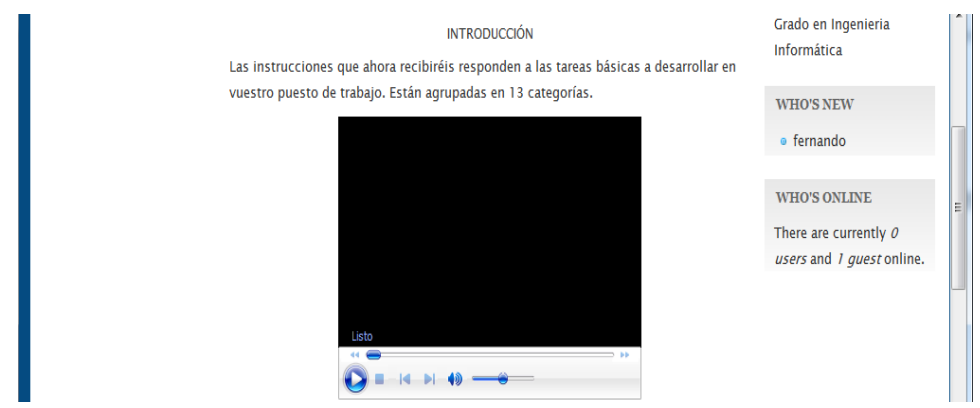

Fig. 3 Introductory video

Figure 3 shows the content of the initial video in which the user can obtain a description of the operation of the application, as well as the use of videos containing the signed orders that correspond to the professional developments to perform in the workplace.

Once the user be in the learning section, the learning process is started, displaying the videos for the different blocks of accomplishments that can occur in the office environment:
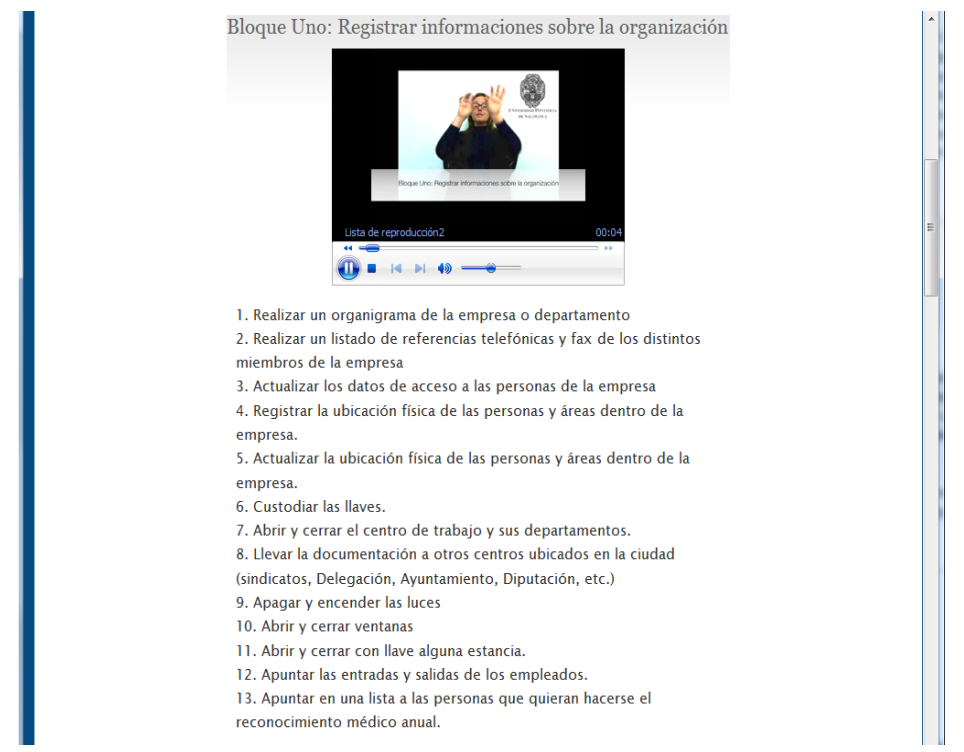

Fig. 4 Learning section 


\section{- Mobile application}

In this work we have designed and developed a mobile application for the platform that allows quick transmission of orders in the office workplace. The application includes voice recognition [16], so that a person at work may transmit voice instruction. These instructions will be recognized by the mobile device, which accesses a remote server and display the video corresponding to the order in sign language.

We revised the related work and the existing technologies to choose the best option for the mobile module. An analysis was made of all mobile platforms on the market to see which is more suited to our requirements. The module was developed for iOS [14], and can be installed on a device like iPad iPhone, as long as it has the same operating system version iOS 5 or above. This module uses an XML file [15] containing the structure of the data to be displayed. This XML file is stored in the cloud, and is parsed by our application. When the application starts, it parses the file and inserts into a table all the blocks, so that the user can choose one of them. Once the user clicks on a block, a screen containing an explicative video will be shown. The videos are also stored in the cloud. The advantages of using a cloud storage are that the content can be updated very easily and without jeopardizing the proper functioning of the application. Below, some screenshots for the developed application are presented, showing its operation.

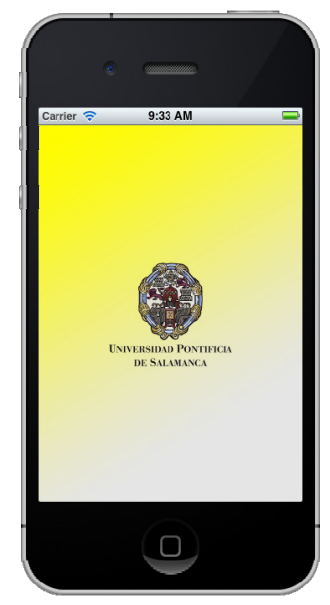

Fig. 5 Main screen of the application

Figure 5 shows the main screen of the application that shows the user at the time of initiation. Once the user clicks on this screen, he can access the playback menu. 


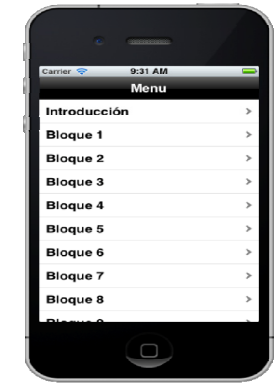

Fig. 6 Blocks scheme of the application

Figure 6 shows the screen with the touch playback options. Playback can be done in blocks or individually. Figure 6 shows a reproduction in blocks.

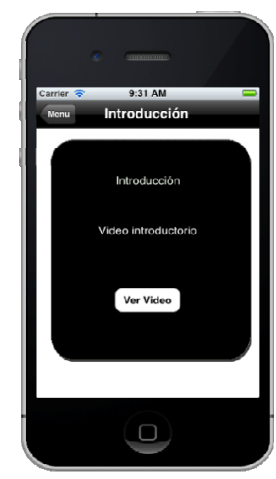

Fig. 7 Detail of a block

Figure 7 shows the playback screen, where the user has the option to view videos. The user can return to the playback of videos or play video.

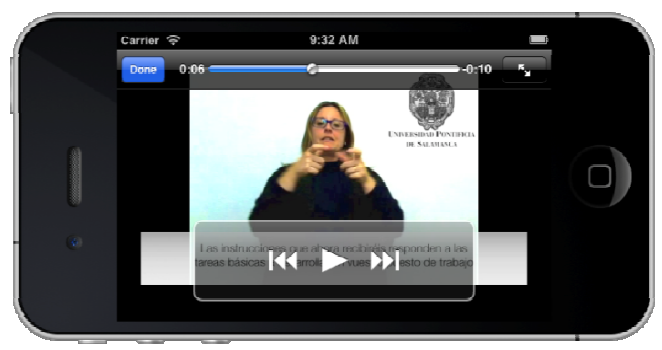

Fig. 8 Example of signed vídeo 
Figure 8 shows the playback screen, where the user is viewing a video. The application was initially developed for iPhone and iPad devices, but can be easily adapted to be executed on mobile devices.

\section{Conclusions}

The new model of labor relations established by the Spanish Royal Decree-Law $3 / 2012$, of 10 February, on urgent measures for labor reform has among its objectives the promotion of inclusion in the labor market of more advantaged groups, including the people with disabilities. [16].

Our aim was to contribute to this goal by means of a technological platform specifically designed to facilitate labor insertion in office environment of people with auditory impairment. The proposed platform has a web interface and an interface for mobile devices, and is based on pre-recorded videos that contain instructions on actions to be performed by the disabled person in the office environment. The web interface was successfully tested in teaching through television, in collaboration with the company CSA and the results have been promising. The application was developed using the Drupal content management system and the iOS5 environment. We reviesed various content management and mobile platforms, leading to the conclusion that drupal and iOS5 were the most appropriated. However, it is necessary to indicate that the platform is easily adaptable to other technologies. Moreover, the mobile application was tested in an office environment. Users and FAPSCyL specialists have highlighted the utility and advantages of the application. A test was designed with 10 basic tasks performed by 3 disabled people before and after the platform presented in this paper was installed. The platform provided a new tool that contributed to increase the percentage of completed tasks up to $85 \%$, when the initial percentage (without the platform) was $42 \%$. The disabled users have remarked the ease of understanding of instructions they receive from their supervisors and ease of use of the system.

Acknowledgments. This work has been supported by the Ambientes Inteligentes con Tecnología Accesible para el Trabajo (AZTECA), CDTI. Proyecto de Cooperación Interempresas. IDI-20110345.

\section{References}

1. Calvo Prieto, J.C. (ed.): La sordera. Un enfoque socio-familiar. Amarú Ediciones, Salamanca (1999)

2. CNSE. Las personas sordas en España. Situación actual. Necesidades y demandas. Confederación Nacional de Sordos de España, Madrid (1996)

3. CNSE. Retos para el siglo XXI: Resoluciones del II Congreso de la Confederación de Sordos de España. Confederación Nacional de Sordos de España, Madrid (1998)

4. FESORCV. Minguet, A. (Coord.): asgos sociológicos y culturales de las personas sordas: una aproximación a la situación del colectivo de Personas Sordas en la Comunidad Valenciana. Federación de Personas Sordas de la Comunidad Valenciana, FESORD C.V., Valencia (2001) 
5. FIAPAS. Jáudenes (Coord.): Manual Básico de Formación Especializada sobre Discapacidad Auditiva. Confederación Española de Padres y Amigos de los Sordos, Madrid (2004)

6. Levy-Leboner, C.: Gestión de competencias. Gestión 2000. Barcelona (1997)

7. Ley 27/2007, de 23 de octubre. Madrid: BOE no 255, del 24-10-2007, pp. 43251-43259 (2007)

8. Ley 5/2002, de 19 de junio de las Cualificaciones y de la Formación Profesional. BOE del 20 de junio de, Madrid (2002)

9. Real Decreto 229/2008, de 1 de febrero, que recoge siete cualificaciones de la Familia profesional Administración y Gestión. BOE del 25 de febrero de, Madrid (2008)

10. Real Decreto-Ley 3/2012 de 10 de febrero, de medidas urgentes para la reforma del mercado laboral. BOE del 11 de febrero de, Madrid (2012)

11. Weiser, M.: The computer for the 21st century. Scientific American 265(3), 94-104 (1991)

12. Federación de Asociaciones de Personas Sordas de Castilla y León (FAPSCyL) (2012), http: / / www. fapscl .org/

13. Buytaert, Dries: Drupal (2012), http: / / drupal .org/

14. Napier, R., Kumar, M.: iOS 5 Programming Pushing the Limits. Wiley (2011) ISBN: 978-1119961321

15. Goldfarb, C.F., Prescod, P.: XML Handbook with CD-ROM. Prentice Hall PTR, Upper Saddle River (2001)

16. Reynolds, D.A.: An overview of automatic speaker recognition technology. In: 2002 IEEE International Conference on Acoustics, Speech, and Signal Processing (ICASSP), vol. 4, pp. 4072-4075 (2002) 